\title{
REVIEW
}

\section{Circadian rhythms in mitochondrial respiration}

\author{
Paul de Goede,"*, Jakob Wefers ${ }^{2, *}$, Eline Constance Brombacher ${ }^{3}$, Patrick Schrauwen² and Andries Kalsbeek ${ }^{1,3,4}$ \\ 'Department of Clinical Chemistry, Laboratory of Endocrinology, Academic Medical Center (AMC), University of Amsterdam, Amsterdam, \\ The Netherlands \\ 2Department of Human Biology and Human Movement Sciences, Maastricht University Medical Center (MUMC), Maastricht, The Netherlands \\ ${ }^{3}$ Department of Endocrinology and Metabolism, Academic Medical Center (AMC), University of Amsterdam, Amsterdam, The Netherlands \\ ${ }^{4}$ Hypothalamic Integration Mechanisms Group, Netherlands Institute for Neuroscience (NIN), Amsterdam, The Netherlands \\ Correspondence should be addressed to A Kalsbeek: a.kalsbeek@nin.knaw.nl \\ *(P de Goede and J Wefers contributed equally to this work)
}

\begin{abstract}
Many physiological processes are regulated with a 24-h periodicity to anticipate the environmental changes of daytime to nighttime and vice versa. These 24-h regulations, commonly termed circadian rhythms, among others control the sleep-wake cycle, locomotor activity and preparation for food availability during the active phase (daytime for humans and nighttime for nocturnal animals). Disturbing circadian rhythms at the organ or whole-body level by social jetlag or shift work, increases the risk to develop chronic metabolic diseases such as type 2 diabetes mellitus. The molecular basis of this risk is a topic of increasing interest. Mitochondria are essential organelles that produce the majority of energy in eukaryotes by converting lipids and carbohydrates into ATP through oxidative phosphorylation. To adapt to the ever-changing environment, mitochondria are highly dynamic in form and function and a loss of this flexibility is linked to metabolic diseases. Interestingly, recent studies have indicated that changes in mitochondrial morphology (i.e., fusion and fission) as well as generation of new mitochondria are dependent on a viable circadian clock. In addition, fission and fusion processes display diurnal changes that are aligned to the light/darkness cycle. Besides morphological changes, mitochondrial respiration also displays diurnal changes.

Disturbing the molecular clock in animal models leads to abrogated mitochondrial rhythmicity and altered respiration. Moreover, mitochondrial-dependent production of reactive oxygen species, which plays a role in cellular signaling, has also been linked to the circadian clock. In this review, we will summarize recent advances in the study of circadian rhythms of mitochondria and how this is linked to the molecular circadian clock.
\end{abstract}

\section{Introduction}

Due to the continuous rotation of the earth around its own axis and around the sun, the earthly environment exposes its inhabitants to predictable periodic changes, most notably daily changes in lightness-darkness and food availability and seasonal changes in photoperiod. In order to adapt and anticipate to the daily changes in the environment, most organisms have evolved an internal timing system, the so-called circadian clock system. Via this system, humans and other mammals for instance lower their heart rate and body temperature to prepare themselves for sleep. This biological clock system also enables the body to switch its main metabolic substrate 
from carbohydrates during the active phase (daytime in humans and nighttime in nocturnal animals) to lipids during the inactive phase (nighttime in humans, daytime in nocturnal animals), to ensure adequate substrate usage by the main metabolic pathways that can provide cellular ATP.

In mammals, the circadian timekeeping system consists of a central pacemaker in the brain located in the suprachiasmatic nuclei (SCN) in the anterior hypothalamus. This central pacemaker receives input from (day) light, which it uses to synchronize its circadian rhythm of approx. $24 \mathrm{~h}$ with the exact 24 -h daily rhythm of the rotations of the earth around its axis. Subsequently, the central pacemaker in the SCN can synchronize the different peripheral tissue clocks in the body via various signaling cascades (Fig. 1). The peripheral tissue clocks additionally receive synchronizing inputs from several other cues, such as body temperature, locomotor activity, feeding behavior and the dietary composition of food. On a molecular level, both the central and peripheral clocks use a similar mechanism that consists of a transcriptional-translational feedback loop (TTFL). The core of this TTFL consists of a negative and positive limb that ensures oscillation of the timing system, as well as several auxiliary mechanisms that allow for adjusting properties of the timing system, such as period length and flexibility or robustness of the clock mechanism (Fig. 1). The molecular circadian clock and its time keeping function are conserved in all tissues of the body, but cellular functions downstream of the molecular clock mechanism are tissue specific and only a small number of clock-controlled genes show rhythmicity in all tissue (Zhang et al. 2014a). Moreover, both the central and peripheral tissue clocks can be entrained to specific time cues (Zeitgebers) such as light for the SCN, feeding for the liver and physical activity for skeletal muscle.

Mitochondria are often termed the cell's powerhouses as these organelles are the main source of cellular ATP, which is produced during aerobic respiration. Within these cytosolic double-membrane organelles glucose, lipids,

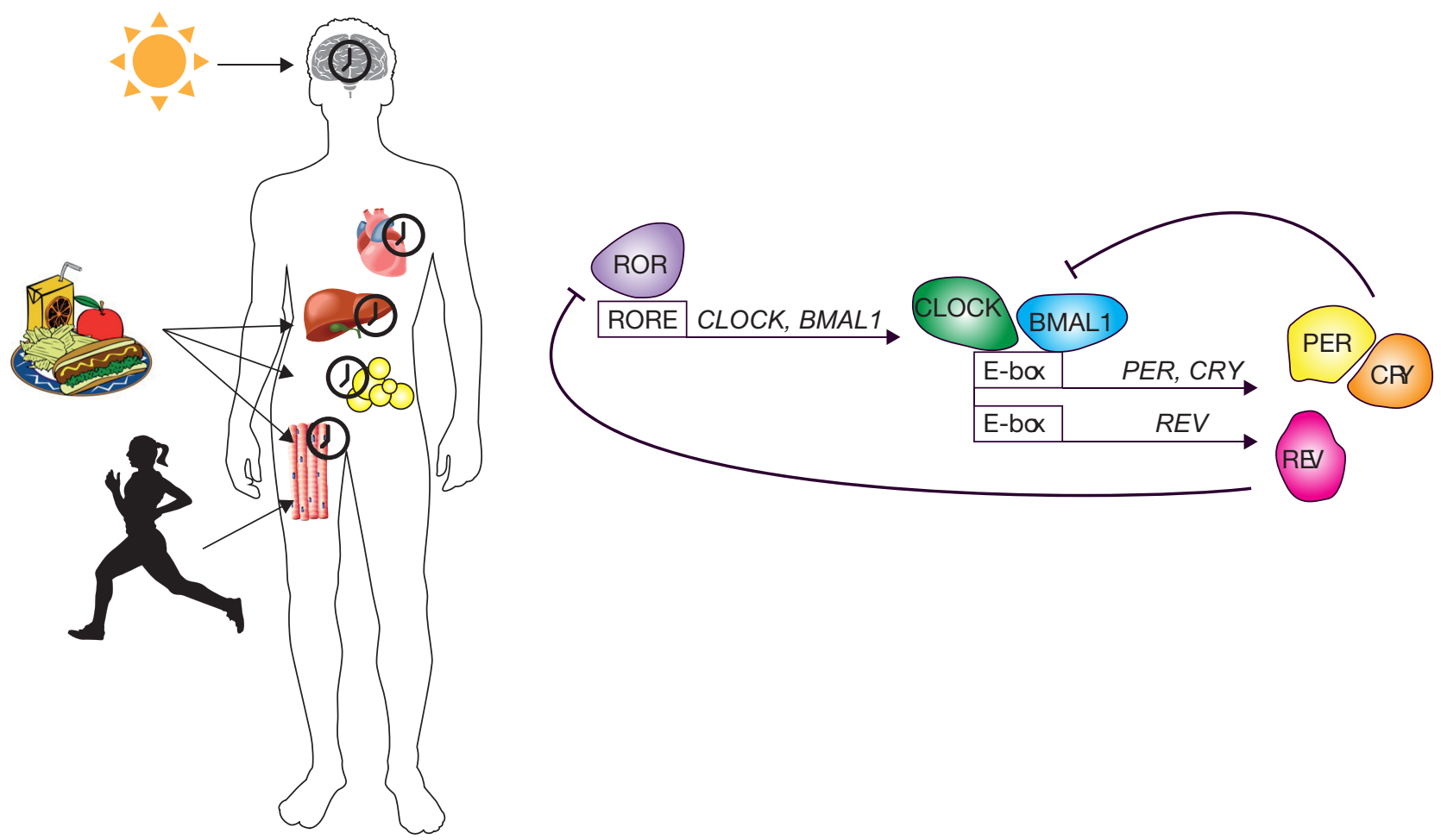

Figure 1

The molecular circadian clock and tissue-specific clocks in the body. CLOCK and BMAL1 form a heterodimer that binds to E-box regulatory sequences $P E R / C R Y$ and other genes. PER and CRY form a repressor complex, which inhibitsCLOCK-BMAL1 when sufficient levels are reached. The second feedback loop involves nuclear orphan receptors, which bind to the retinoic acid-related orphan receptor response elements (RORES) in CLOCK and BMAL1 regulatory sequences. Retinoid-related orphan receptor (ROR) activates transcription of CLOCK and BMAL1. The CLOCK-BMAL1 complex induces transcription of REVERBA and REVERBB (REV), which subsequently compete with ROR, in order to inhibit transcription of CLOCK and BMAL1. Circadian clocks exist in almost every cell and exhibit tissue-specific rhythmicity, orchestrated by the central circadian clock in the suprachiasmatic nucleus. Synchronization takes place via neural, hormonal and behavioral signals. 
ketogenic and amino acid derivatives are metabolized in the tricarboxic acid cycle (TCA cycle) in order to generate $\mathrm{H}^{+}$and electrons, which in turn are needed for the electron transfer chain (ETC) to produce ATP. ATP production during the aerobic ETC is highly efficient as compared to ATP production during anaerobic fermentation, gaining over tenfold higher yields (Hochachka 1993, Mitchell 1996, Rich 2003). Other, lesser known, roles of mitochondria include cellular signaling, cell growth and proliferation as well as cell death. Mitochondria contain their own (circular) DNA, mitochondrial DNA (mtDNA), as well as transcription and translation machinery and therefore can replicate independent of normal cell division. This mitochondrial replication allows for the presence of many (up to several thousand) mitochondria per cell (Cummins 2002, Cole 2016).

Recently, interest in regulation of mitochondria by the circadian timekeeping system has gained interest as more and more evidence indicates that the biological clock also orchestrates the functioning of mitochondria. This review will provide an overview of the recent findings on how the circadian clock and mitochondrial functioning are interrelated and will focus on mitochondrial morphology and mitochondrial respiration.

\section{Mitochondrial morphology and functioning}

The energy producing capacity of mitochondria is strongly related to their abundance and morphology. In fact, mitochondrial morphology, number and functioning are highly dynamic. On a tissue level, it is well established that mitochondrial content, in terms of mtDNA, mRNA, protein content as well as enzymatic activity and respiration rates can differ up to a 100-fold between tissue types and that mitochondrial content and functioning is also species dependent (Leary et al. 1998, Forner et al. 2006, Hulbert et al. 2006, Fernández-Vizarra et al. 2011). Strikingly, a small proportion of the mitochondrial proteome seems to be unique to individual tissue types such as liver, skeletal muscle and heart (Forner et al. 2006, 2009). Moreover, also the substrate preference of mitochondria can differ for tissue types, e.g. glycolytic type IIa muscle fibers preferably oxidize glycolytic substrates, whereas oxidative type II muscle fibers also more readily utilize fatty acids and ketones (Forner et al. 2006). On a cellular level, the number of mitochondria present in an individual cell is highly variable, likely reflecting the metabolic needs of the cell. In order to suffice these highly variable changes in supply and demand of energy, cells need an efficient machinery for both mitochondrial biogenesis as well as

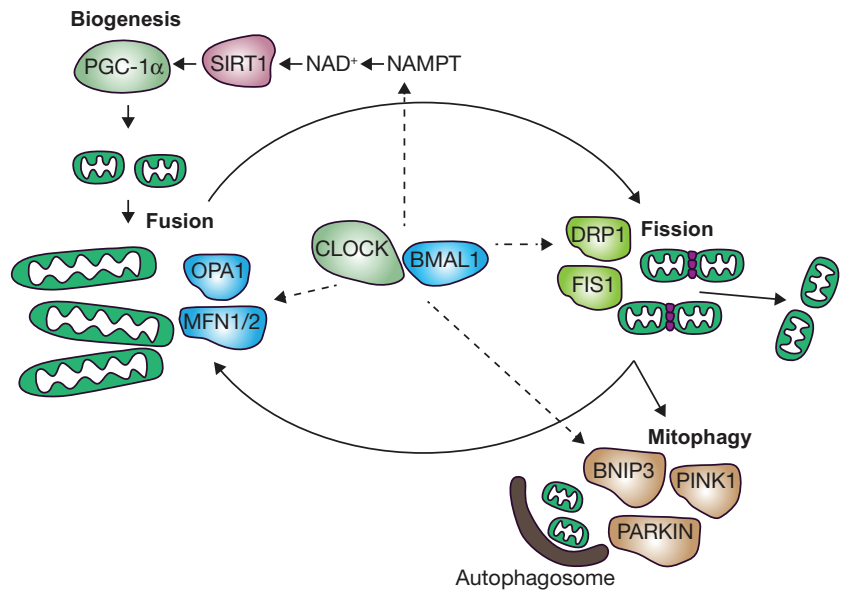

Figure 2

Model for circadian regulation of mitochondrial homeostasis. To maintain healthy mitochondria, mitochondria are continuously formed and removed during the active phase. The CLOCK-BMAL1 complex stimulates mitochondrial biogenesis and mitophagy through activation of SIRT1. Mitochondrial biogenesis is regulated by transcription factor PGC1A. Newly formed mitochondria fuse to form a tubular network. Mitophagy is preceded by mitochondrial fission in order to form fragmented mitochondria which can be taken up by an autophagosome. Both fusion and fission are influenced by CLOCK-BMAL1. A number of regulatory proteins regulate fusion (OPA1, MFN1/2), fission (FIS1, DRP1) and mitophagy (PINK1, BNIP1, PARKIN) processes.

mitophagy, the process of mitochondrial breakdown. The balance between mitochondrial biogenesis and mitophagy determines the mitochondrial content of the cell. PGC1A and PGC1B are considered to be key proteins for mitochondrial biogenesis, key proteins for mitophagy are PINK1, PARKIN and BNIP3.

Aside from the overall number of mitochondria present in a cell, the size and shape of mitochondria also plays an important role in their energy production. Mitochondria can be present not only as small individual organelles (fissioned mitochondria), but also as extensive tubular networks resulting from the fusion of multiple mitochondria (Fig. 2). These elongated, fused, mitochondria display a higher mitochondrial respiration and can be found in energy-consuming cells as well as during energy-consuming processes. Key players for mitochondrial fusion are mitofusion (MFN) 1 and 2 and optic atrophy 1 (OPA1). Key players for mitochondrial fission are dynamin-related protein 1 (DRP1) and fission 1 (FIS1) (Mitra 2013). This interplay between mitochondrial fusion and fission is known as mitochondrial dynamics.

\section{Biogenesis}

Mitochondrial biogenesis is not simply the increase in number of mitochondria, but is often also accompanied

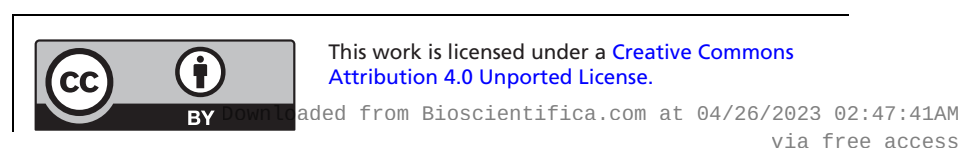


by an increase in mitochondrial size and mass, i.e. changes in mitochondrial morphology (Jornayvaz \& Shulman 2010). As the mtDNA only contains 37 genes, mitochondrial biogenesis requires the correct synthesis and import of approximately 1000-1500 proteins encoded by nuclear DNA. Overexpression of transcription factor PGC1A provided the first evidence of its role in mitochondrial biogenesis. In muscle cells, overexpression of PGC1A stimulated mtDNA copy number as well as the proliferation of mitochondria (Wu et al. 1999). Later in vivo studies indicated that expressing PGC1A in glycolytic mice muscles activated genes of mitochondrial oxidative metabolism and that inducing PGC1A expression through muscle stimulation increased mitochondrial biogenesis (Lin et al. 2002, Irrcher et al. 2003). PGC1 $\alpha$ activity can be regulated through phosphorylation by AMPK and deacetylation by SIRT1 (Diaz \& Moraes 2008). These posttranslational modifications of PGC1A likely provide a direct link between cellular nutrient status and mitochondrial biogenesis since both AMPK and SIRT1 can act as a nutrient sensors. Importantly, proteins of the PGC1 family are also involved in the regulation of metabolic processes such as gluconeogenesis, fatty acid beta-oxidation as well as oxidative phosphorylation (Lin et al. 2005).

\section{Mitophagy}

Mitophagy is the regulated removal of damaged mitochondria by autophagosomes. Through mitophagy, cells keep a healthy pool of mitochondria, and also can adapt to the ever-changing metabolic demand of the cells. Additionally, mitophagy can provide the cell with nutrients from the phagocytized mitochondria during nutrient deprivation. Furthermore, mitophagy has been suggested to play a role in cell differentiation and maturation as well as pathogenesis (Youle \& Narendra 2011, Ding \& Yin 2012, Saito \& Sadoshima 2015). Key proteins involved in mammalian mitophagy are PINK1, PARKIN and BNIP3. Although mitophagy itself is difficult to measure, several proxy methods have been employed to quantify mitophagy including key protein analysis with immunoblots and fluorescence microscopy, as well as electron microscopy using immunogold antibodies (Ding \& Yin 2012).

\section{Mitochondrial dynamics}

Mitochondrial morphology can drastically vary between cell types and tissues, and this is likely a response

$$
\begin{aligned}
& \text { http://jme.endocrinology-journals.org } \\
& \text { https://doi.org/10.1530/JME-17-0196 }
\end{aligned}
$$

to metabolic cues from cells and their environment (Wai \& Langer 2016). Through the process of fusion, mitochondria can form extensive networks, and conversely, through the process of fission, mitochondria can also show a strongly fragmented presence in a cell. It is thought that through fusion an exchange of material between healthy mitochondria is enabled while fission allows for separation of intact and damaged mitochondria (Ni et al. 2015). Both fission and fusion are strongly regulated by the cell, and disruption of mitochondrial dynamics is associated with aging and several diseases, including diabetes, and neurodegenerative diseases such as Huntington, Parkinson and Alzheimer's disease (Chen \& Chan 2009, Ni et al. 2015, Sebastián et al. 2017).

\section{Circadian control of mitochondrial function}

\section{Biogenesis}

Mitochondrial biogenesis is affected by many external and environmental factors, including exercise, caloric restriction, oxidative stress and cellular division, renewal and differentiation (Jornayvaz \& Shulman 2010). Since the energy demand of cells fluctuates throughout the day, it is to be expected that mitochondrial abundance, morphology and/or functioning also fluctuates throughout the day. Indeed, more and more evidence indicates that mitochondria react to or maybe even anticipate the daily changes in nutrient availability that most organisms experience. Therefore, circadian control of these mitochondrial properties can be expected. Several studies investigated whether mitochondrial biogenesis, mitochondrial content, mitochondrial dynamics or mitochondrial functioning were regulated by the circadian clock (Table 1). Mitochondrial content, as measured by levels of mtDNA, protein content or mitochondrial mass was not found to be different throughout the day, neither in human skeletal muscle (van Moorsel et al. 2016) nor in synchronized immortalized human hepatic cells (Cela et al. 2016). In human muscle, the marker of mitochondrial biogenesis, PGC1A, was not found to be rhythmically expressed, but in synchronized immortalized human hepatic cells, mRNA levels of PGC1A were found to be rhythmic, with peak levels of expression proximal to peak levels of BMAL1 expression. Animal models also show different results on the regulation of mitochondrial biogenesis by the circadian timing system. In mice, liver protein levels of PGC1A and PGC1B were found to be oscillating with peak levels at the onset of the active phase and in the middle of the inactive phase, respectively

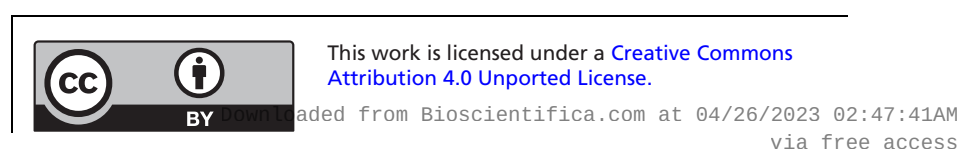


Table 1 Overview of findings on mitochondrial rhythms.

\begin{tabular}{|c|c|c|c|c|c|}
\hline Species & KO tissue & KO gene & Main findings & In tissue & Ref. \\
\hline Human & & & $\begin{array}{l}\text { NR mtDNA } \\
\text { NR mt protein } \\
\text { NR mt mass } \\
\text { NR PGC1A } \\
\sim \text { PINK1 and FIS1 } \\
\sim \text { OCR }\end{array}$ & Muscle & van Moorsel et al. (2016) \\
\hline Human (cells) & & & $\begin{array}{l}\sim P G C 1 A \\
\sim \text { Gluthathione }\end{array}$ & Hepatic (HepG2) & Cela et al. (2016) \\
\hline Mouse & & & $\begin{array}{l}\sim \mathrm{PGC1A} \\
\sim \mathrm{PGC1B}\end{array}$ & Liver & Liu et al. (2007) \\
\hline Rat & & & $\begin{array}{l}\sim P g c 1 \\
\text { aNR Pgc1b }\end{array}$ & Muscle and BAT & de Goede et al. (2017) \\
\hline Rat & & & $\sim P g c 1 a$ & Liver & de Goede et al. (2017) \\
\hline Mouse & & & $\begin{array}{l}\sim \text { mt dynamics } \\
\sim \text { mt membrane } \\
\text { potential } \\
\sim \text { Phagocytic/bactericidal } \\
\text { activity }\end{array}$ & Macrophages & Oliva-Ramírez et al. (2014) \\
\hline Rat & & & $\sim O C R$ & Brain & Simon et al. (2003) \\
\hline Mouse & & & Several ETC mRNAs & SCN, but not liver & Panda et al. (2002) \\
\hline Mouse & & & $\sim P R X I I I$ & $\begin{array}{l}\text { Adrenal gland, BAT } \\
\text { and heart }\end{array}$ & Kil et al. (2015) \\
\hline Mouse & & & $\sim \mathrm{PRXI}$ & Liver & Edgar et al. (2012) \\
\hline Mouse & Global & Pgc1a KO & $\begin{array}{l}\text { NR TCA/ETC gene } \\
\text { expression }\end{array}$ & Liver and muscle & Liu et al. (2007) \\
\hline Mouse & Global & Per2 KO & $\begin{array}{l}- \text { mt abundance } \\
- \text { mtDNA } \\
\uparrow \text { resistance to ROS \& UV } \\
\text { cytotoxity } \\
\uparrow N A D H / N^{+} D^{+}\end{array}$ & Embryonic fibroblast & Magnone et al. (2015) \\
\hline Mouse & Global & $\begin{array}{l}\text { Bmal1 KO and } \\
\Delta \text { Clock }\end{array}$ & $\begin{array}{l}\downarrow \text { muscle force, mt } \\
\text { volume, OCR } \\
\text { NR Pgc1a, Pgc1b }\end{array}$ & Muscle & Andrews et al. (2010) \\
\hline Mouse & Global & Per1/2 dKO & $\begin{array}{l}\text { NR mt rate-limiting } \\
\text { proteins } \\
\downarrow \text { OCR }\end{array}$ & Liver & Neufeld-Cohen et al. (2016) \\
\hline Mouse & Global & Bmal1 KO & $\downarrow P g c 1 b$ & $\begin{array}{l}\text { Primary mouse } \\
\text { hepatocyte }\end{array}$ & Zhang et al. (2014b) \\
\hline Mouse & Global & $\Delta$ Clock & $\begin{array}{l}\text { NR several mt genes } \\
- \text { Pgc1 } \\
\text { aNR Pgc1b } \\
\downarrow \text { and NR SIRT3 } \\
\text { NR OPA1 } \\
\text { NR mt oxidative stress } \\
\text { markers } \\
\text { NR SOD acetylation and } \\
\text { activity }\end{array}$ & Liver & Gong et al. (2015) \\
\hline Mouse & Global & Reverba KO & $\begin{array}{l}\downarrow \text { mtDNA } \\
\downarrow \text { mt abundance } \\
\text { mt morphology altered } \\
\downarrow \text { Pgc1a/PGC1A } \\
\downarrow \text { ETC gene and protein } \\
\text { expression } \\
\downarrow \text { respiration }\end{array}$ & Muscle & Woldt et al. (2013) \\
\hline Mouse & Global & $\Delta$ Clock & $\begin{array}{l}\downarrow \text { ATP synthase complex } \\
\text { proteins }\end{array}$ & Muscle & McCarthy et al. (2007) \\
\hline Mouse & Global & Cry1/2 dKO & $\begin{array}{l}\uparrow \mathrm{mt} \text { reserve capacity } \\
\uparrow \text { exercise performance }\end{array}$ & Myotubes & Jordan et al. (2017) \\
\hline Mouse & Global & Bmal1 KO & NR NADH levels & Epidermal stem cells & Stringari et al. (2015) \\
\hline Mouse & Global & Bmal1 KO & $\begin{array}{l}\downarrow \text { mt proton gradient } \\
\downarrow \text { ATP/ADP }\end{array}$ & Pancreas ( $\beta$-cells) & Lee et al. (2011) \\
\hline
\end{tabular}


Table 1 Continued

\begin{tabular}{|c|c|c|c|c|c|}
\hline Species & KO tissue & KO gene & Main findings & In tissue & Ref. \\
\hline Mouse & Liver & Bmal1 KO & $\begin{array}{l}\text { - mtDNA } \\
- \text { mt biogenesis enzymes } \\
\downarrow \text { OCR } \\
\uparrow \text { Atp5b }\end{array}$ & Liver & Peek et al. (2013) \\
\hline Mouse & Liver & Bmal1 KO & $\begin{array}{l}\text { NR mt Biogenesis } \\
\text { mRNAs } \\
\text { NR mt morphology } \\
\uparrow \text { mt size/surface } \\
\text { NR several fission/ } \\
\text { mitophagy mRNAs } \\
\text { - Mfn1 Mfn2 Opa1 } \\
\downarrow \text { several fission/ } \\
\text { mitophagy proteins } \\
\uparrow \text { MFN1 } \\
\downarrow \text { OCR } \\
\uparrow \text { superoxide levels }\end{array}$ & Liver/hepatocyes & Jacobi et al. (2015) \\
\hline Mouse & Liver (cells) & $\begin{array}{l}\text { Cry1, Cry2, Per1 or } \\
\text { Per2 siRNA }\end{array}$ & $\uparrow \mathrm{OCR}$ & Hepa 1-6 cell line & Jacobi et al. (2015) \\
\hline Human (cells) & HEPG2 & $B M A L 1 \mathrm{KO}$ & $\downarrow \mathrm{mt}$ respiration & Hepatic (HepG2) & Scrima et al. (2016) \\
\hline Mouse & Muscle & Bmal1 KO & $\downarrow$ and NR PDH activity & Muscle & Dyar et al. (2014) \\
\hline Mouse & Cardiac & Bmal1 KO & $\begin{array}{l}\downarrow \text { mt protein } \\
\downarrow \text { mt abundance } \\
- \text { mtDNA } \\
\text { mt morphology altered } \\
\downarrow \text { ETC gene expression } \\
\text { and activity } \\
\downarrow P g c 1 a \\
\downarrow M f n 1 \text { and Opa } 1 \\
\downarrow N A D^{+} \text {and NADH }\end{array}$ & Cardiac & Kohsaka et al. (2014) \\
\hline Mouse & Cardiomyocyte & $\Delta$ Clock & $\begin{array}{l}\text { - mtDNA, mt number, } \\
\text { mt density } \\
\text { - mt morphology } \\
\downarrow \text { OCR (subsarcolemmal } \\
\text { fraction) } \\
\text { - OCR (intra } \\
\text { myofibrillar) }\end{array}$ & $\begin{array}{l}\text { Heart } \\
\text { (subsarcolemmal } \\
\text { and intra } \\
\text { myofibrillar) }\end{array}$ & Bray et al. (2008) \\
\hline Mouse & $\begin{array}{c}\text { Pancreas } \\
(\beta \text {-cell) }\end{array}$ & Bmal1 KO & $\begin{array}{l}\downarrow \mathrm{mt} \text { membrane } \\
\text { potential gradient } \\
\downarrow \text { ATP/ADP } \\
\uparrow \text { ROS accumulation }\end{array}$ & Pancreas ( $\beta$-cells) & Lee et al. (2011) \\
\hline
\end{tabular}

For KO studies, findings are represented as differences compared to wt animals.

-, no changes; , rhythmic (i.e. with at least 2 time points); $\Delta$ Clock, $\Delta$ Clock19 mice; dKO, double knockout; KO, knockout; mt, mitochondrial; NR, nonrhythmic or altered/dampened rhythms.

(Liu et al. 2007). We found Pgc1a mRNA to be rhythmically expressed in rat muscle, brown adipose tissue (BAT) and liver. $P g_{c} 1 b$ was found not to be rhythmically expressed in muscle or BAT (de Goede et al. 2017, Oosterman et al. in preparation). It should be noted, however, that indirect measures of mitochondrial abundance and biogenesis such as protein and mRNA expression of Pgc1a and the abundance of mtDNA do not necessarily translate into mitochondrial biogenesis itself. Less indirect evidence for circadian clock control of mitochondrial content comes from several KO models in rodents and cell lines. KO of Per2 in mouse embryonic fibroblasts did not lead to an altered number of mitochondria, as determined

\begin{tabular}{|lr}
\hline http://jme.endocrinology-journals.org & $\odot 2018$ The authors \\
https://doi.org/10.1530/JME-17-0196 & $\begin{array}{r}\text { Published by Bioscientifica Ltd. } \\
\text { Printed in Great Britain }\end{array}$
\end{tabular}

by fluorescent microscopy, nor to altered mtDNA copy numbers (Magnone et al. 2015). Global Bmal1 KO as well as Clock $\Delta 19$-mutant mice showed reduced contractile muscle force and profound reductions in muscle mitochondrial volume and respiratory function, which were associated with altered expression levels of Pgc1 $a$ and Pgc1b (Andrews et al. 2010). In isolated liver mitochondria from global Per1/2 dKO mice, the daily fluctuations in ratelimiting mitochondrial enzymes such as CPT1 and PDH and proteins involved in oxidative phosphorylation were abolished. In addition, the daily average protein content of PDH was decreased, indicating that PER proteins are involved in the regulation of key mitochondrial protein

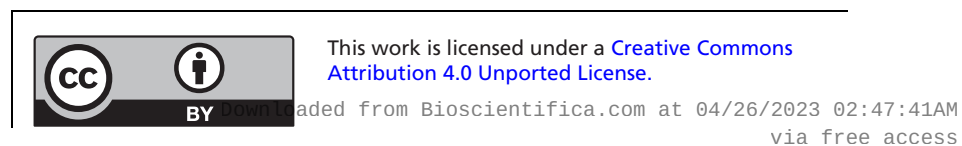


synthesis and thus possibly in mitochondrial biogenesis itself. However, no differences in daily average mtDNA copy number were found compared to wild-type mice (Neufeld-Cohen et al. 2016). In a liver-specific Bmal1 KO mouse model, the mitochondrial content in liver was also unaffected (Peek et al. 2013), as well as liver Pgc1a mRNA and protein content. Pgc1b in contrast showed impaired rhythmicity in mice liver upon global Clock mutation as well as reduced mRNA levels in hepatocytes from global Bmal1 KO mice (Zhang et al. 2014b, Gong et al. 2015). These differing findings between $P g c 1 a$ and $P g c 1 b$ seem to implicate that $P g c 1 b$, but not $P g c 1 a$ levels are controlled by the positive limb of the circadian clock. Heart-specific Bmal1 KO mice did not show altered mtDNA content in cardiac tissue, but microscopic assessment indicated a diminished number of mitochondria and altered morphology of these mitochondria (Kohsaka et al. 2014). Interestingly, cardiac Pgc1a levels were decreased in this $\mathrm{KO}$ model while mitochondrial protein content was also decreased. In a depletion model of Reverba, which is a negative mediator of the positive limb of the molecular circadian clock TTFL (Fig. 1), mice myoblasts showed decreased mitochondrial DNA levels, which is indicative of decreased mitochondrial abundance (Woldt et al. 2013). Moreover, PGC1A protein and mRNA expression were reduced both in cell cultures as well as in the soleus and quadriceps muscles of mice upon Reverba $\mathrm{KO}$, whereas overexpression of Reverba in cell cultures increased Pgc1a mRNA expression. Taken together, these data indicate that $P g c 1 a$ and not $P g c 1 b$ is the main regulator of circadian rhythmicity of mitochondrial biogenesis as only impairment of Pgcla leads to reduced mitochondrial abundance and differences in mitochondrial volume and protein content. Additionally, these data suggest that, with the exception of cardiac tissue, Pgc1a transcription is not affected by the positive limb of the TTFL, but disruption of the negative limb does decreases PGC1A protein expression and mitochondrial content. A possible connection between the TTFL and PGC1A are nutrient sensors such as AMPK and SIRT1, since it has been shown that REVERBA increased PGC1A activity through AMPK-dependent activation of Sirt1 (Woldt et al. 2013). Conversely, PGC1A has been shown to affect the functioning of the core clock machinery by increasing transcription of Bmal1 and Clock via interactions with RORa and RORb (Liu et al. 2007). Moreover, depletion of PGC1A impaired circadian rhythms of activity, body temperature and metabolic rate in mice, indicating that Pgc1a affects not only the molecular clock, but also the behavioral rhythms ultimately.

\section{Mitophagy}

Seemingly contradictory, Pgc1a levels fluctuated throughout the day, but mitochondrial mass or content was not found to be fluctuating throughout the day, but did seem to be affected by disturbing the molecular clock in most of the animal and human (cell) studies described earlier. In a different study in mice liver, mitochondrial biogenesis was found to be diurnally regulated in a Bmal1dependent manner, as liver-specific Bmal1 KO eliminated the diurnal pattern of mitochondrial biogenesis (Jacobi et al. 2015). If mitochondrial biogenesis is indeed fluctuating while mitochondrial content does not change, as the previously mentioned indirect markers of biogenesis suggest, then the process of mitochondrial removal should act as a counter-mechanism to maintain mitochondrial homeostasis. Mitochondria are removed from the cytosol of the cell via mitochondrial-specific autophagy, called mitophagy. For autophagy, it has been shown that the number of autophagic vacuoles vary throughout the day in various tissue types (Pfeifer \& Scheller 1975, Pfeifer 1981, Ma et al. 2012). Additionally, liver-specific knockout of Bmal1 abolished diurnal regulation of Bnip3 and diminished the levels of autophagy markers as well as the flux in autophagy itself (Ma et al. 2011). However, time of day dependence of mitophagy, has been studied less. Mitophagy and the morphology of the mitochondria are inherently linked with each other as mitochondrial fission is required for mitophagy and apoptosis (Twig et al. 2008). Elongated and fused mitochondria are protected from mitophagy, possibly due to their extended size, often forming tubular networks that simply do not fit into the autophagosomes (Gomes et al. 2011, Rambold et al. 2011).

\section{Mitochondrial dynamics}

As mentioned before, key players for mitophagy are PINK1, PARKIN as well as mitochondrial autophagy receptors such as BNIP3; for mitochondrial fusion, the key proteins are considered to be MFN1 and MFN2 and OPA1, while key players for mitochondrial fission are DRP1 and FIS1 (Gomes \& Scorrano 2013, Mitra 2013). Mitophagy seems to have evolved as a key mechanism for keeping a healthy pool of mitochondria in the cell, eliminating excessive/superfluous and damaged mitochondria (Gomes \& Scorrano 2013). First evidence of timely regulation of fission, fusion and mitophagy came from BMAL1 ChIP-seq experiments showing that mediators of fission such as Fis1, as well as mitophagy regulators such

This work is licensed under a Creative Commons Attribution 4.0 Unported License.

ded from Bioscientifica.com at $04 / 26 / 2023$ 02:47:41AM via free access 
as Pink1 and Bnip3 were direct targets of BMAL1 and their expression levels were also found to be affected upon liver-specific Bmal1 KO (Rey et al. 2011, Koike et al. 2012, Jacobi et al. 2015). Fission-related protein DRP1 and regulators of fusion MFN1/2 and OPA1 were not found to be direct targets of the hepatic molecular clock (Jacobi et al. 2015). In contrast, in cardiac tissue fusion-related Mfn1 and Opa1, mRNA expression was downregulated in heart-specific Bmal1 KO mice, suggesting that Bmal1 indirectly affects mitochondrial fusion in the heart (Kohsaka et al. 2014). In human skeletal muscle and mice liver, PINK1 protein levels showed opposite acrophases as compared to FIS1, suggesting that these processes do not take place at the same time (Jacobi et al. 2015, van Moorsel et al. 2016). In human muscle, PINK1 protein levels peaked in the middle of the active phase, while in mouse liver, PINK1 peaked at the end of the active phase. Confocal microscope morphology studies showed that in synchronized murine macrophages, the mitochondria follow a rhythmic pattern in their fission/fusion dynamics and that a more fused state correlated with an increased membrane potential of mitochondria as well as increased macrophage phagocytic and bactericidal activity (OlivaRamírez et al. 2014). This suggests that mitochondria prepare themselves for high energy demanding activity such as during the active phase through the process of mitochondrial fusion. Nevertheless, these results could not be reproduced in an ex vivo setting, as no diurnal differences were found in membrane potential nor phagocytic capacity of the macrophages when using freshly isolated macrophages (Oliva-Ramírez et al. 2014). These findings suggest that mitophagy takes mainly place during the active phase and that both fission and mitophagy are regulated by the positive limb of the TTFL. Another possible regulator of mitophagy is SIRT1. Addition of nicotinamide, a precursor of $\mathrm{NAD}^{+}$, increased mitophagy in human fibroblasts and this was dependent on the $\mathrm{NAD}^{+}$sensor SIRT1 (Kang \& Hwang 2009, Jang et al. 2012). Interestingly, SIRT1 target PGC1A levels peak during the active period (Liu et al. 2007, Diaz \& Moraes 2008). Taken together, these findings seem to suggest that both mitochondrial biogenesis and mitophagy are enhanced during the active phase and that both processes are perhaps regulated via SIRT1. Mitochondrial quality control thus seems to be regulated by the circadian clock, either via BMAL1 or more indirectly via SIRT1, leading to increased turnover of mitochondrial content during the active phase, but without clear alterations in mitochondrial content throughout the day.
However, further studies on these subjects are desired, as most studies on mitochondrial biogenesis, mitophagy and mitochondrial dynamics do not directly measure these processes, but instead rely on biomarkers of these processes.

\section{Circadian control of mitochondrial respiration}

Energy requirements of all organs are dependent on their activity levels. Furthermore, substrate usage can differ between carbohydrate and fat oxidation in the active and inactive phase. Thus, it would be efficient to prepare mitochondrial respiratory capacity according to the light and darkness phase. Since expression of clock-controlled genes exhibits high organ specificity and peripheral oscillators use individual entrainment signals (i.e., feeding and physical activity), we summarize the key literature findings separately for the different organs (Table 1).

An important confounder in the investigation of clock-controlled mitochondrial processes is the influence of pervasive external factors also showing daily rhythmicity, most notably nutrient availability. Most processes in vivo are not only controlled by the biological clock, but also by other factors such as feeding and activity state and the light-darkness cycle. To investigate the contribution of the biological clock specifically, it is necessary to tease apart the influence of the biological clock from all behavior-related influences. Over the last decades, a number of techniques have become available that make it feasible to study the biological clock at the system and organ level. In rodent models, genetic disruption of the biological clock allows to study the isolated influence of a disturbed clock on mitochondrial processes. Frequently used models in this research comprise the disruption of the TTFL, mainly targeting Bmal1, Clock, Per2 and Cry1. Alternatively, disrupting natural feeding-fasting cycles by using time-restricted feeding paradigms have been applied in many different forms and demonstrated to influence biological rhythms of different organs (Hatori \& Panda 2015). Furthermore, keeping animals fasted and in constant dark conditions before collecting the tissues of interest prevents the acute influence of light and feeding (Peek et al. 2015). In addition, in vitro studies can be used to study cells that are isolated of potentially confounding rhythmic influences, such as feeding or neuronal and hormonal signals. After synchronizing the cells by e.g. serum shock, circadian rhythms of the TTFL and downstream 
processes are largely maintained and can be measured at several time points. As a downside, in vitro studies do not allow to study the complex regulation of the biological clock on the organ or system level.

\section{Brain}

One of the earliest observations indicating that mitochondrial function is variable over the day comes from studies in the brain. Mitochondrial oxygen consumption, measured in isolated mitochondria from whole-brain homogenates, was highest in the middle of the resting phase. This was either in the absence of ADP (state 4 respiration) or upon ADP stimulation (state 3 respiration) (Simon et al. 2003). Furthermore, the respiratory control ratio (RCR; state 3 /state 4 ), a measure of how efficient mitochondrial respiration is coupled to ATP production, showed diurnal differences. In the SCN of mice, over 300 genes exhibit rhythmic expression over $24 \mathrm{~h}$ (Panda et al. 2002). Interestingly, several of these genes code for components of the ETC in mitochondria and peak toward the end of the light phase. These results suggest influence of the molecular clock over energyproviding processes in SCN neurons to match increased metabolic demand to the higher activity in the light phase, i.e. both in nocturnal and diurnal species, highest firing rates in SCN neurons are observed during the light period (Sato \& Kawamura 1984, Meijer et al. 1998, Nakamura et al. 2008).

\section{Liver}

A large part of the hepatic transcriptome, proteome and metabolome exhibits tissue-specific circadian rhythmicity and has been studied extensively in cell and animal models. Therefore, it is not surprising that important functions of cellular energy metabolism, such as mitochondrial respiration are under circadian control. Disrupting Bmal1 transcription by siRNA in a liver-derived cell line (HepG2) led to a decrease in mitochondrial respiration (Scrima et al. 2016). In mice, genetic ablation of Bmal1 at the whole-body level resulted in a decreased oxygen consumption rate (OCR) in isolated liver mitochondria (Peek et al. 2013). Interestingly, OCR upon addition of a fatty acid substrate was lower at both the end and the beginning of the subjective darkness (i.e. active) phase in this study, suggesting overall lower mitochondrial respiration upon circadian disturbance. Further, the same study identified that specifically beta-oxidation and the
TCA cycle, catabolic steps upstream of the ETC, caused the decrease in respiration (Peek et al. 2013). In support of these findings, a liver-specific knockdown of Bmal1 also resulted in lower OCR in response to a glycolytic substrate of mitochondria in both the active and inactive phase of mice (Jacobi et al. 2015). These results indicate that the peripheral molecular clock exerts control over mitochondrial respiration. In addition to the influence of BMAL1 on mitochondrial respiration also PER1/2, negative elements of the TTFL, seem to be important regulators. In mice, ablation on the whole-body level of Per1 and Per2 resulted in a decrease in mitochondrial OCR over the day when using either a fatty acid or glycolytic substrate (Neufeld-Cohen et al. 2016). In stark contrast, abrogation of the transcription of Per1 or Per2 in the Hepa 1-6 cell line, resulted in increased mitochondrial OCR (Jacobi et al. 2015). It could be speculated that the differences in the model (i.e. cell line vs in vivo model) may contribute to the contradicting effect on mitochondrial respiration. However, an explanation of the mechanism that leads to this different response is missing.

While these studies show that an intact circadian clock is necessary for normal mitochondrial respiration, it has also been shown that respiration exhibits an intrinsic circadian rhythm. Mitochondrial OCR in response to a glycolytic substrate in isolated hepatocytes from mice was shown to be higher near the end of the active phase (Jacobi et al. 2015). In liver tissue from fasted mice, ${ }^{14} \mathrm{C}$-labeled substrate oxidation exhibited robust 24-h oscillations with a peak toward the end of the resting phase (Peek et al. 2013). Intriguingly, when using substrates that require the glycolytic pathway (pyruvate), OCR was shown to peak at the beginning of the inactive period, whereas OCR upon fatty acid substrates (palmitoyl CoA) peaked $8 \mathrm{~h}$ earlier at the end of the active period (Neufeld-Cohen et al. 2016). This difference in peak respiration might be due to the rate-limiting enzymes of the respective pathways. Protein levels of pyruvate dehydrogenase $(\mathrm{PDH}$, rate limiting for the glycolytic pathway) and palmitoyl-transferase 1 (CPT1, rate limiting for the fatty acid pathway) displayed a rhythm that corresponded to the rhythm of OCR upon the same substrate and was dependent on normal PER1/2 function (Fig. 3) (Neufeld-Cohen et al. 2016). While these studies uniformly show diurnal changes in mitochondrial respiration, the time of peak respiration varies clearly. Since these studies were performed with either whole tissue, cells or isolated mitochondria, it could be speculated that the extra-mitochondrial and extra-cellular environment determines the difference in time keeping. Moreover, 


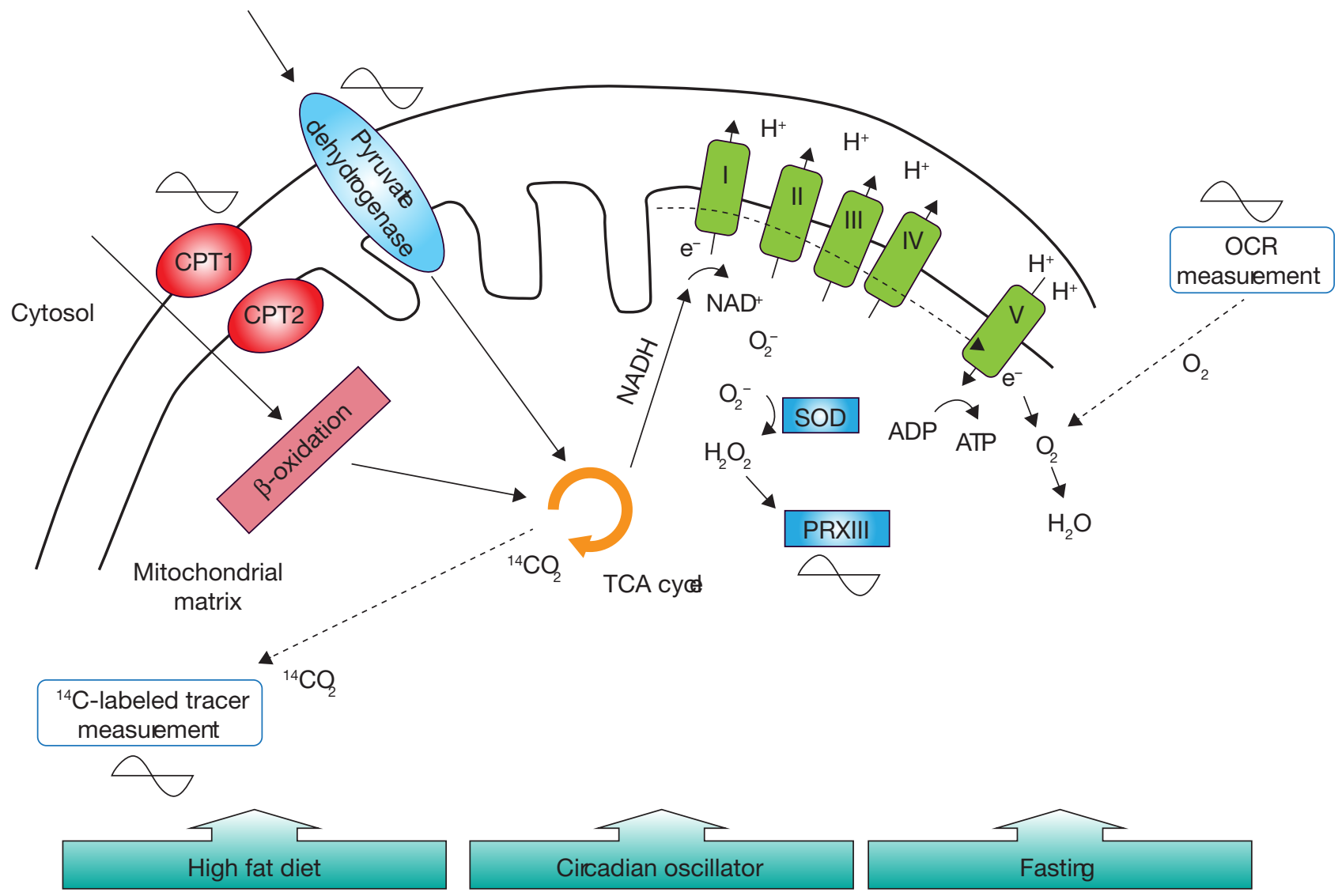

Figure 3

Mitochondrial respiration and ROS production show rhythmic activity. Mitochondrial respiration is the result of electron transfer to molecular oxygen as final step in the electron transport chain (ETC). Respiration is experimentally determined by measuring OCR. In addition, ${ }^{14} \mathrm{C}$-labeled substrates can be used to assess mitochondrial energy production by measuring ${ }^{14} \mathrm{CO}_{2}$. Substrate transport (CPT1/2, PDH) and catabolic processes ( $\beta$-oxidation, TCA cycle) also exhibit circadian rhythms and are under control of the circadian clock. Consequently, mitochondrial respiration is rhythmic in various cell and animal models. Mitochondria are also a source of ROS that are produced in various sites, such as complex I of the ETC. Superoxides $\left(\mathrm{O}_{2}{ }^{-}\right)$are scavenged by superoxidedismutase (SOD) and reduced to $\mathrm{H}_{2} \mathrm{O}_{2}$. Several antioxidant proteins such as peroxiredoxins (PRXIII) subsequently eliminate $\mathrm{H}_{2} \mathrm{O}_{2}$. Also antioxidant proteins and ROS production display circadian activity. Additionally, feeding behavior, including diet composition, also affects mitochondrial processes.

external influences, such as nutrients and feeding/fasting, seem to exert additional control over circadian rhythms of respiration. Mice on a high-fat diet (HFD) lose rhythmicity in respiration, which highlights the vulnerability of the coordinated mitochondrial function by the circadian clock (Neufeld-Cohen et al. 2016). Moreover, hepatocytes from fasted mice display no difference in OCR over the day (Jacobi et al. 2015). However, fasting might affect specifically mitochondrial respiration at the level of the ETC, as ${ }^{14} \mathrm{C}$-labeled substrate oxidation remains rhythmic upon fasting condition (Peek et al. 2013).

Together, these studies indicate that hepatic mitochondrial respiration is influenced by the circadian clock, but it remains to be answered, which steps exactly in the pathway of substrate oxidation are under circadian control and how the molecular circadian clock regulates these pathways.

\section{Muscle}

Physical activity patterns in animals under laboratory conditions exhibit clear circadian rhythmicity, which is abrogated upon disruption of the circadian clock (Mosko \& Moore 1979, McDearmon et al. 2006). Furthermore, human studies show that exercise performance is variable throughout the day (Conroy \& O'Brien 1974, Facer-Childs \& Brandstaetter 2015). To regulate bioenergetic demand in skeletal muscle, the circadian clock might impose control over important metabolic processes such as mitochondrial respiration. Disrupting the circadian clock by muscle-specific Bmal1 ablation resulted in a substantial decrease in ${ }^{14} \mathrm{C}$-glucose oxidation in isolated mouse diaphragms (Dyar et al. 2014). While this decrease in glucose oxidation could be due to impaired respiration (which was not assessed separately in this study), activity

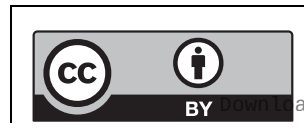

This work is licensed under a Creative Commons Attribution 4.0 Unported License. 
of the rate-limiting enzyme pyruvate dehydrogenase (PDH), upstream of respiration, was lower over a 24-h period. This suggests that, similar to liver mitochondria, important catabolic enzymes could determine fluctuations in mitochondrial respiration. A dysfunctional circadian clock, induced by whole-body Bmal1 abrogation, also directly impairs respiration. Thus, mitochondrial oxygen consumption under ADP-titration (state 3 respiration) was decreased markedly in gastrocnemius and diaphragm muscle of Bmal1 KO mice, resulting in a decrease in RCR (Andrews et al. 2010). Similarly, whole-body knock down of the accessory clock component Reverba in mice resulted in decreased state 3 respiration in isolated mitochondria and in permeabilized muscle fibers of the soleus muscle (Woldt et al. 2013). In addition, protein levels of respiratory chain complexes 1,3 and 4 were strongly decreased. Interestingly, overexpressing Reverba improved ex vivo mitochondrial respiration (Woldt et al. 2013). Impairments of components of the ETC might also occur due to a defective CLOCK protein. At least on the transcriptional level, a dominant-negative Clock mutation resulted in a decrease in expression levels of several subunits of the ATP synthase (McCarthy et al. 2007). Of note, a recent study found that deletion of Cry 1 and Cry2, negative regulators of BMAL1/CLOCK, resulted in increased mitochondrial reserve capacity in primary myotubes and increased exercise performance in mice (Jordan et al. 2017). This effect was possibly mediated by PPARD, since CRY1/2 exerts a repressor function under normal conditions. Together, these studies highlight that mitochondrial respiration in skeletal muscle is dependent on the molecular circadian clock machinery. However, also in muscle, the exact properties of this regulation, remain to be investigated.

Whether mitochondrial respiration exhibits circadian rhythmicity has been investigated in a limited number of studies. Cell lines in culture can display robust circadian oscillations after they are synchronized by an overwriting signal, e.g. after being exposed to serum shock (Peek et al. 2015). Accordingly, mouse skeletal muscle derived C2C12 myotubes show circadian rhythmicity (monitored over $48 \mathrm{~h}$ ) in oxidation of ${ }^{14} \mathrm{C}$-labeled fatty acids (Peek et al. 2013). Interestingly, ${ }^{14} \mathrm{C}$-labeled glucose as substrate resulted in a similar rhythmic oxidation, which was shifted by $4 \mathrm{~h}$. In the same study, also OCR, a direct measurement of mitochondrial respiration, showed a circadian rhythm over $48 \mathrm{~h}$. While this suggests direct control of the circadian clock on mitochondrial respiration in myocytes, it should be noted that crucial components of upstream processes, such as in beta-oxidation and glycolysis, also exhibit circadian rhythmicity (Hodge et al. 2015). This adds another layer of complexity to the circadian regulation of substrate utilization. A recent study from our lab reported daily fluctuations in mitochondrial respiration in human skeletal muscle tissue, measured in permeabilized muscle fibers from muscle biopsies (van Moorsel et al. 2016). OCRs during APD-stimulated state 3 respiration showed pronounced diurnal changes with peak and trough at 23:00 $\mathrm{h}$ and 13:00 $\mathrm{h}$, respectively. Mitochondrial respiration was assessed using fatty acids, glutamate and succinate as substrates. Interestingly, at 23:00 h BMAL1 also exhibited peak expression levels, while PER2 expression was at its trough (van Moorsel et al. 2016).

Taken together, ample evidence indicates that mitochondrial oxidative metabolism in skeletal muscle is under control of the peripheral circadian clock.

\section{Other tissues}

The circadian control of mitochondrial respiration has also been shown in other tissues such as the heart, beta-cells and epidermal stem cells. In the heart of Clock ${ }^{\Delta 19}$-deficient mice, the subsarcolemmal fraction of mitochondria showed a decreased state 3 OCR, while intramyofibrillar mitochondria were not affected (Bray et al. 2008). Another study demonstrated that heart-specific Bmal1 knockdown in mice is associated with downregulated expression levels of genes belonging to the TCA cycle and ETC, together with reduced complex I activity (Kohsaka et al. 2014). In a model of epidermal stem cell imaging, the amount of free NADH was used as a proxy marker for oxidative metabolism and showed fluctuations with a circadian pattern. These fluctuations were not present in cells derived from Bmal1-deficient mice (Stringari $e t a l$. 2015). Another potential implication for clock-controlled mitochondrial respiration was reported in a study using insulin producing beta-cells. Here, deleting Bmal1 resulted in an increase in uncoupling protein 2 (UCP2), which resulted in a decreased inner mitochondrial membrane proton gradient and thus to a decrease in the ATP/ADP ratio (Lee et al. 2011). Since the ATP/ADP ratio is an important cue for insulin secretion, this observation may link the molecular circadian clock machinery via mitochondrial respiration to insulin secretion.

\section{Mitochondrial redox homeostasis and the circadian clock}

Mitochondrial respiration is connected to production of reactive oxygen species (ROS) and mitochondria are major

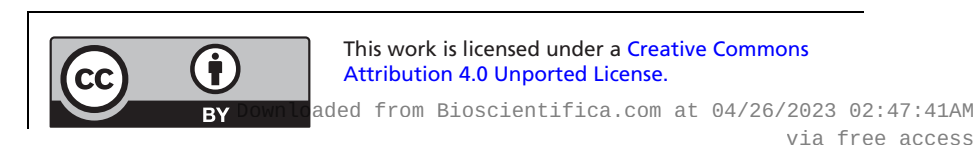


ROS production sites in the cell (Sena \& Chandel 2012). While the perils of ROS have been thoroughly debated in the past, attention has more recently shifted toward the physiological necessity of ROS to maintain cellular viability. Importantly, ROS play a major role as signaling molecules that regulate various crucial cellular processes, such as autophagy, immunity, differentiation and response to hypoxia (Sena \& Chandel 2012). Disturbance of redox homeostasis can impair important signaling events, which can result in cell damage, making it necessary to tightly regulate ROS production and removal. Several proteins are involved in elimination of ROS in the mitochondria and cytosol. Notable antioxidant proteins include catalase, glutathione, thioredoxin and peroxiredoxin (Reczek \& Chandel 2015). In addition, uncoupling proteins in the mitochondrial membrane may alleviate ROS production (Mailloux \& Harper 2011).

Keeping redox homeostasis in balance depends on ROS production and ROS scavenging. Generation of ROS in mitochondria occurs when electrons are occasionally transferred to oxygen $\left(\mathrm{O}_{2}\right)$, generating a superoxide molecule $\left(\mathrm{O}_{2}^{-}\right)$(Fig. 3). Superoxides are eliminated by catalyzing them into hydrogen peroxide $\left(\mathrm{H}_{2} \mathrm{O}_{2}\right)$ by the enzyme superoxide dismutase (SOD). Generation of superoxides occurs at several sites, but complexes of the ETC are a major source (Mailloux 2015). Production rates of mitochondrial superoxides are mainly determined by the redox state of electron carriers (i.e. ratio of NADH/ $\mathrm{NAD}^{+}$) and the inner mitochondrial membrane proton gradient (Sena \& Chandel 2012). An efficient way to alleviate superoxide production might be the dissipation of the proton gradient by uncoupling proteins (Mailloux \& Harper 2011). Interestingly, expression levels of $U c p 3$ in rat heart exhibit diurnal variations with highest levels in the resting phase (Stavinoha et al. 2004). Moreover, measuring ROS production in a model of synchronized HepG2 cells revealed highest levels at the time of peak OCR (Cela et al. 2016). Since it is methodologically cumbersome to directly assess superoxide production, most studies focus on measuring antioxidant status (Mailloux 2015). A study in athletes found that plasma levels of glutathione and catalase are higher in the evening compared to the morning, suggesting higher capacity to cope with oxidative stress (Ammar et al. 2015). Mechanistic studies in mouse MEFs revealed increased catalase levels upon constitutive overexpression of Reverba, suggesting a direct link to the molecular clock (Sengupta et al. 2016). In a study of mouse liver, glutathione expression was rhythmic and peaked at the beginning of the active phase ( $\mathrm{Xu}$ et al. 2012).
In addition, the mitochondrial isoform of peroxiredoxin (PRXIII) in mice peaks at the end of the active phase in adrenal gland, brown adipose tissue and heart (Kil et al. 2015). Similarly, in mouse liver tissue, the cytosolic and nuclear isoform PRXI was reported to be higher toward the end of the active phase (Edgar et al. 2012). Together, these studies suggest that ROS production occurs during the active phase.

Another important regulation of ROS production might be facilitated through fusion and fission processes. In primary hepatocytes from Bmal1-depleted mouse liver, superoxide levels were increased and mitochondria were swollen. Upon induction of FIS1, a mitochondrial fissionpromoting protein, superoxide levels were decreased, suggesting that BMAL1 can influence ROS production through morphological changes of mitochondria, which is in line with the effects of fission on mitochondrial respiration described earlier (Jacobi et al. 2015).

Recent evidence shows that the mitochondrial redox system is linked to the biological clock through the $\mathrm{NAD}^{+}$-dependent deacetylase SIRT1. The cytoplasmic and nuclear enzyme SIRT1 is activated in response to varying $\mathrm{NAD}^{+}$levels and causes deacetylation of among others BMAL1 in a rhythmic manner (Nakahata et al. 2008). In addition, SIRT1 has also been shown to deacetylate PER2, reducing its activity and affecting the circadian rhythmicity of core clock genes (Asher et al. 2008). It is important to emphasize that SIRT1 also regulates the activity of PGC1A, an important activator of mitochondrial biogenesis (Rodgers et al. 2005). There also appears to be indirect regulation of redox metabolism by the biological clock through the NAMPT-NAD+-SIRT3 axis. The ratelimiting enzyme in the $\mathrm{NAD}^{+}$salvage pathway, NAMPT, is controlled by the core molecular clock (Nakahata et al. 2009, Ramsey et al. 2009). Another pathway involves the nicotinamide riboside (NR) pathway, in which key enzymes of $\mathrm{NAD}^{+}$synthesis (i.e. NRK1 and NMNAT) are under clock gene control (Mauvoisin et al. 2017). In agreement, $\mathrm{NAD}^{+}$levels in cell and animal models have been shown to fluctuate with core molecular clock oscillations (Nakahata et al. 2009, Ramsey et al. 2009). The activity of the mitochondrial deacytelase SIRT3 is NAD+ dependent and has important regulatory functions for mitochondria proteins. Importantly, the acetylation status of mitochondrial proteins also shows a clear temporal separation. In a recent study, SIRT3-targeted proteins in mouse liver were found predominantly acetylated during the resting phase of the animals (Mauvoisin et al. 2017). Several proteins of redox homeostasis in mitochondria are under control of SIRT3. Among these regulated 
proteins is mitochondrial SOD2, which catalyzes the initial reduction of superoxide into $\mathrm{H}_{2} \mathrm{O}_{2}$ and exhibits rhythmic acetylation and activity in mouse liver. In mice with the Clock $^{\Delta 19}$ mutation, this rhythm in SOD2 acetylation and activity is abrogated (Gong et al. 2015). In addition to changes in $\mathrm{NAD}^{+}$by NAMPT, the balance of $\mathrm{NADH} / \mathrm{NAD}^{+}$can also be regulated through changes in NADH levels. Since NADH is oxidized to NAD ${ }^{+}$by complex I of the ETC, a decrease in its activity results in a higher NADH/NAD ${ }^{+}$ratio. Mutations in Per2 led to a decreased complex I activity and to a higher NADH/NAD+ ratio, indicating that the molecular circadian clock has multiple ways to adjust the redox balance (Magnone et al. 2015). This is of importance, since NADH is required for the efficient binding of the heterodimer BMAL1/CLOCK (Rutter et al. 2001). Adding to this, recent evidence showed that NADH levels exhibit circadian oscillations (Huang et al. 2016). It should, however, be noted that the $\mathrm{NAD}^{+} / \mathrm{NADH}$ ratio has multiple crucial functions in mitochondrial homeostasis that extend far beyond its involvement in ROS production.

In order to convey information to other cytosolic compartments, redox metabolites from the mitochondria, such as $\mathrm{H}_{2} \mathrm{O}_{2}$, must be transported into the cytosol. An intricate regulatory system, which shows circadian activity, has evolved to facilitate this transport. In mitochondria, PRXIII is the main scavenger for $\mathrm{H}_{2} \mathrm{O}_{2}$ and gets oxidized. Subsequently, PRXIII can be recycled by another enzyme, thioredoxin. High $\mathrm{H}_{2} \mathrm{O}_{2}$ levels lead to overoxidation of PRXIII, protecting it from being recycled (Rhee \& Kil 2016). In a study of mouse BAT, lung and heart, overoxidized PRXIII peaks at the end of the active phase (Kil et al. 2015). Recently, a model of circadian regulation of $\mathrm{H}_{2} \mathrm{O}_{2}$ signaling has been proposed in which PRXIII overoxidation by high $\mathrm{H}_{2} \mathrm{O}_{2}$ levels leads to spillover of $\mathrm{H}_{2} \mathrm{O}_{2}$ from mitochondria into the cytosol. Once $\mathrm{H}_{2} \mathrm{O}_{2}$ is in the cytosol, it can exert several functions, such as activating the mitogen-activated protein kinase (MAPK) signaling pathway or decreasing steroidogenesis in the adrenal gland (Kil et al. 2012, Rhee \& Kil 2016). Interestingly, $\mathrm{H}_{2} \mathrm{O}_{2}$ in the cytosol might also act as starting signal for a negative feedback loop, which leads to complete recycling of PRXIII in the mitochondria and thus to abrogation of $\mathrm{H}_{2} \mathrm{O}_{2}$ transport into the cytosol (Rhee $\&$ Kil 2016). The latter mechanism has been postulated to regulate corticosterone production in a diurnal fashion in mice, in addition to the well-known input from the HPA axis (Kil et al. 2012).

Taken together, accumulating evidence indicates that mitochondrial ROS production and scavenging shows similar diurnal fluctuations as mitochondrial oxidative phosphorylation. In addition to diurnal ROS variation due to circadian regulation of oxidative phosphorylation, it appears that the molecular circadian clock has direct links to important regulatory steps of ROS production and scavenging. An intriguing finding is the discovery of a secondary feedback loop which links mitochondrial $\mathrm{H}_{2} \mathrm{O}_{2}$ production to intracellular signaling.

\section{Conclusion}

More and more evidence indicates that the circadian clock and mitochondrial functioning are related. Most available evidence shows how the circadian clock controls the abundance and morphology of mitochondria by regulating biogenesis, fission/fusion and mitophagy. Additionally, several studies suggest that mitochondrial functioning also is regulated by the circadian clock as $\mathrm{KO}$ studies show altered mitochondrial respiration and ROS metabolism, although in these studies, it is difficult to separate effects on substrate availability and mitochondrial function itself. Conversely, direct evidence for mitochondrial regulation of feedback to the circadian clockwork is very limited.

However, for a better understanding of how mitochondrial morphology and functioning change throughout the day, more experiments are needed. Performing imaging and respiration assays throughout the day in different tissues seems to be essential in order to get a clearer picture whether morphology and respiration oscillate throughout the day, whether this is tissue dependent and whether this is related to the molecular clock, substrate availability or a combination of both. Furthermore, data on other regulators such as hormone signaling and the autonomic nervous system, both outputs of the central clock, are scarce, but potentially also exert influences on mitochondrial functioning. One first candidate hormone to investigate is melatonin, which for a long time has been known to be both a hormonal output of the central clock as well as an antioxidant.

Declaration of interest

The authors declare that there is no conflict of interest that could be perceived as prejudicing the impartiality of this review.

\section{Funding}

This work was supported by a grant from the Netherlands Organisation for Scientific Research (NWO; TOP grant number 40-00812-98-14047, 2015).

This work is licensed under a Creative Commons Attribution 4.0 Unported License. 


\section{References}

Ammar A, Chtourou H, Hammouda O, Trabelsi K, Chiboub J, Turki M, AbdelKarim O, El Abed K, Ben Ali M, Hoekelmann A, et al. 2015 Acute and delayed responses of C-reactive protein, malondialdehyde and antioxidant markers after resistance training session in elite weightlifters: effect of time of day. Chronobiology International 32 1211-1222. (https://doi.org/10.3109/07420528.2015.1079215)

Andrews JL, Zhang X, McCarthy JJ, McDearmon EL, Hornberger TA, Russell B, Campbell KS, Arbogast S, Reid MB, Walker JR, et al. 2010 CLOCK and BMAL1 regulate MyoD and are necessary for maintenance of skeletal muscle phenotype and function. PNAS $\mathbf{1 0 7}$ 19090-19095. (https://doi.org/10.1073/pnas.1014523107)

Asher G, Gatfield D, Stratmann M, Reinke H, Dibner C, Kreppel F, Mostoslavsky R, Alt FW \& Schibler U 2008 SIRT1 regulates circadian clock gene expression through PER2 deacetylation. Cell 134 317-328. (https://doi.org/10.1016/j.cell.2008.06.050)

Bray MS, Shaw CA, Moore MWS, Garcia RAP, Zanquetta MM, Durgan DJ, Jeong WJ, Tsai J-Y, Bugger H, Zhang D, et al. 2008 Disruption of the circadian clock within the cardiomyocyte influences myocardial contractile function, metabolism, and gene expression. American Journal of Physiology: Heart and Circulatory Physiology 294 H1036-H1047.

Cela O, Scrima R, Pazienza V, Merla G, Benegiamo G, Augello B, Fugetto S, Menga M, Rubino R, Fuhr L, et al. 2016 Clock genesdependent acetylation of complex I sets rhythmic activity of mitochondrial OxPhos. Biochimica et Biophysica Acta (BBA): Molecular Cell Research 1863 596-606. (https://doi.org/10.1016/j. bbamcr.2015.12.018)

Chen H \& Chan DC 2009 Mitochondrial dynamics-fusion, fission, movement, and mitophagy-in neurodegenerative diseases. Human Molecular Genetics 18 R169-R176. (https://doi.org/10.1093/hmg/ ddp326)

Cole LW 2016 The evolution of per-cell organelle number. Frontiers in Cell and Developmental Biology 4 85. (https://doi.org/10.3389/ fcell.2016.00085)

Conroy RT \& O'Brien M 1974 Proceedings: diurnal variation in athletic performance. Journal of Physiology $23651 \mathrm{P}$.

Cummins J 2002 The role of maternal mitochondria during oogenesis, fertilization and embryogenesis. Reproductive BioMedicine Online $\mathbf{4}$ 176-182. (https://doi.org/10.1016/S1472-6483(10)61937-2)

de Goede P, Sen S, Oosterman JE, Foppen E, Jansen R, la Fleur SE, Challet E \& Kalsbeek A 2017 Differential effects of diet composition and timing of feeding behavior on rat brown adipose tissue and skeletal muscle peripheral clocks. Neurobiology of Sleep and Circadian Rhythms 4 24-33. (https://doi.org/10.1016/j.nbscr.2017.09.002)

Diaz F \& Moraes C 2008 Mitochondrial biogenesis and turnover. Cell Calcium 44 24-35. (https://doi.org/10.1016/j.ceca.2007.12.004)

Ding W-X \& Yin X-M 2012 Mitophagy: mechanisms, pathophysiological roles, and analysis. Biological Chemistry 393 547-564. (https://doi. org/10.1515/hsz-2012-0119)

Dyar KA, Ciciliot S, Wright LE, Biensø RS, Tagliazucchi GM, Patel VR, Forcato M, Paz MIP, Gudiksen A, Solagna F, et al. 2014 Muscle insulin sensitivity and glucose metabolism are controlled by the intrinsic muscle clock. Molecular Metabolism 3 29-41. (https://doi. org/10.1016/j.molmet.2013.10.005)

Edgar RS, Green EW, Zhao Y, van Ooijen G, Olmedo M, Qin X, Xu Y, Pan M, Valekunja UK, Feeney KA, et al. 2012 Peroxiredoxins are conserved markers of circadian rhythms. Nature 485 459-464. (https://doi.org/10.1038/nature11088)

Facer-Childs E \& Brandstaetter R 2015 The impact of circadian phenotype and time since awakening on diurnal performance in athletes. Current Biology 25 518-522. (https://doi.org/10.1016/j. cub.2014.12.036)

Fernández-Vizarra E, Enríquez JA, Pérez-Martos A, Montoya J \& Fernández-Silva P 2011 Tissue-specific differences in mitochondrial activity and biogenesis. Mitochondrion 11 207-213. (https://doi. org/10.1016/j.mito.2010.09.011)

Forner F, Foster LJ, Campanaro S, Valle G \& Mann M 2006 Quantitative proteomic comparison of rat mitochondria from muscle, heart, and liver. Molecular and Cellular Proteomics 5 608-619. (https://doi. org/10.1074/mcp.M500298-MCP200)

Forner F, Kumar C, Luber CA, Fromme T, Klingenspor M \& Mann M 2009 Proteome differences between brown and white fat mitochondria reveal specialized metabolic functions. Cell Metabolism 10 324-335. (https://doi.org/10.1016/j.cmet.2009.08.014)

Gomes LC \& Scorrano L 2013 Mitochondrial morphology in mitophagy and macroautophagy. Biochimica et Biophysica Acta (BBA): Molecular Cell Research 1833 205-212. (https://doi.org/10.1016/j. bbamcr.2012.02.012)

Gomes LC, Di Benedetto G \& Scorrano L 2011 During autophagy mitochondria elongate, are spared from degradation and sustain cell viability. Nature Cell Biology 13 589-598. (https://doi.org/10.1038/ ncb2220)

Gong C, Li C, Qi X, Song Z, Wu J, Hughes ME \& Li X 2015 The daily rhythms of mitochondrial gene expression and oxidative stress regulation are altered by aging in the mouse liver. Chronobiology International 32 1254-1263. (https://doi.org/10.3109/07420528.2015. 1085388)

Hatori M \& Panda S 2015 Response of peripheral rhythms to the timing of food intake. Methods in Enzymology 552 145-161. (https://doi. org/10.1016/bs.mie.2014.10.027)

Hochachka PW 1993 Surviving Hypoxia: Mechanisms of Control and Adaptation. CRC Press:Boca Raton, FL, USA.

Hodge BA, Wen Y, Riley LA, Zhang X, England JH, Harfmann BD, Schroder EA \& Esser KA 2015 The endogenous molecular clock orchestrates the temporal separation of substrate metabolism in skeletal muscle. Skeletal Muscle 5 17. (https://doi.org/10.1186/s13395015-0039-5)

Huang G, Zhang Y, Shan Y, Yang S, Chelliah Y, Wang H \& Takahashi JS 2016 Circadian oscillations of NADH redox state using a heterologous metabolic sensor in mammalian cells. Journal of Biological Chemistry 291 23906-23914. (https://doi.org/10.1074/jbc.M116.728774)

Hulbert AJ, Turner N, Hinde J, Else P \& Guderley H 2006 How might you compare mitochondria from different tissues and different species? Journal of Comparative Physiology B 176 93-105. (https://doi. org/10.1007/s00360-005-0025-z)

Irrcher I, Adhihetty PJ, Sheehan T, Joseph A-M \& Hood DA 2003 PPARgamma coactivator-1alpha expression during thyroid hormoneand contractile activity-induced mitochondrial adaptations. American Journal of Physiology: Cell Physiology 284 C1669-C1677. (https://doi. org/10.1152/ajpcell.00409.2002)

Jacobi D, Liu S, Burkewitz K, Kory N, Knudsen NH, Alexander RK, Unluturk U, Li X, Kong X, Hyde AL, et al. 2015 Hepatic Bmal1 regulates rhythmic mitochondrial dynamics and promotes metabolic fitness. Cell Metabolism 22 709-720. (https://doi.org/10.1016/j. cmet.2015.08.006)

Jang S, Kang HT \& Hwang ES 2012 Nicotinamide-induced Mitophagy. Journal of Biological Chemistry 287 19304-19314. (https://doi. org/10.1074/jbc.M112.363747)

Jordan SD, Kriebs A, Vaughan M, Duglan D, Fan W, Henriksson E, Huber A-L, Papp SJ, Nguyen M, Afetian M, et al. 2017 CRY1/2 selectively repress PPARס and limit exercise capacity. Cell Metabolism 26 243.e6-255.e6. (https://doi.org/10.1016/j.cmet.2017.06.002)

Jornayvaz FR \& Shulman GI 2010 Regulation of mitochondrial biogenesis. Essays in Biochemistry 47 69-84. (https://doi.org/10.1042/ bse0470069)

Kang HT \& Hwang ES 2009 Nicotinamide enhances mitochondria quality through autophagy activation in human cells. Aging Cell 8 426-438. (https://doi.org/10.1111/j.1474-9726.2009.00487.x)

Kil IS, Lee SK, Ryu KW, Woo HA, Hu M-C, Bae SH \& Rhee SG 2012 Feedback control of adrenal steroidogenesis via H2O2-dependent,
This work is licensed under a Creative Commons Attribution 4.0 Unported License. 
reversible inactivation of peroxiredoxin III in mitochondria. Molecular Cell 46 584-594. (https://doi.org/10.1016/j. molcel.2012.05.030)

Kil IS, Ryu KW, Lee SK, Kim JY, Chu SY, Kim JH, Park S \& Rhee SG 2015 Circadian oscillation of sulfiredoxin in the mitochondria. Molecular Cell 59 651-663. (https://doi.org/10.1016/j.molcel.2015.06.031)

Kohsaka A, Das P, Hashimoto I, Nakao T, Deguchi Y, Gouraud SS, Waki H, Muragaki Y \& Maeda M 2014 The circadian clock maintains cardiac function by regulating mitochondrial metabolism in mice. PLoS ONE (edited by NS Foulkes) 9 e112811. (https://doi. org/10.1371/journal.pone.0112811)

Koike N, Yoo S-H, Huang H-C, Kumar V, Lee C, Kim T-K \& Takahashi JS 2012 Transcriptional architecture and chromatin landscape of the core circadian clock in mammals. Science 338 349-354. (https://doi. org/10.1126/science.1226339)

Leary SC, Battersby BJ \& Moyes CD 1998 Inter-tissue differences in mitochondrial enzyme activity, RNA and DNA in rainbow trout (Oncorhynchus mykiss). Journal of Experimental Biology 201 3377-3384.

Lee J, Kim M-S, Li R, Liu VY, Fu L, Moore DD, Ma K \& Yechoor VK 2011 Loss of Bmal1 leads to uncoupling and impaired glucose-stimulated insulin secretion in $\beta$-cells. Islets 3 381-388. (https://doi.org/10.4161/ isl.3.6.18157)

Lin J, Wu H, Tarr PT, Zhang C-Y, Wu Z, Boss O, Michael LF, Puigserver P, Isotani E, Olson EN, et al. 2002 Transcriptional co-activator PGC- $1 \alpha$ drives the formation of slow-twitch muscle fibres. Nature $\mathbf{4 1 8}$ 797-801. (https://doi.org/10.1038/nature00904)

Lin J, Handschin C \& Spiegelman BM 2005 Metabolic control through the PGC-1 family of transcription coactivators. Cell Metabolism 1 361-370. (https://doi.org/10.1016/j.cmet.2005.05.004)

Liu C, Li S, Liu T, Borjigin J \& Lin JD 2007 Transcriptional coactivator PGC-1alpha integrates the mammalian clock and energy metabolism. Nature 447 477-481. (https://doi.org/10.1038/ nature05767)

Ma D, Panda S \& Lin JD 2011 Temporal orchestration of circadian autophagy rhythm by C/EBP $\beta$. EMBO Journal 30 4642-4651. (https:// doi.org/10.1038/emboj.2011.322)

Ma D, Li S, Molusky MM \& Lin JD 2012 Circadian autophagy rhythm: a link between clock and metabolism? Trends in Endocrinology and Metabolism 23 319-325. (https://doi.org/10.1016/j.tem.2012.03.004)

Magnone MC, Langmesser S, Bezdek AC, Tallone T, Rusconi S \& Albrecht U 2015 The mammalian circadian clock gene Per2 modulates cell death in response to oxidative stress. Frontiers in Neurology 5 289. (https://doi.org/10.3389/fneur.2014.00289)

Mailloux RJ 2015 Teaching the fundamentals of electron transfer reactions in mitochondria and the production and detection of reactive oxygen species. Redox Biology 4 381-398. (https://doi. org/10.1016/j.redox.2015.02.001)

Mailloux RJ \& Harper M-E 2011 Uncoupling proteins and the control of mitochondrial reactive oxygen species production. Free Radical Biology and Medicine 51 1106-1115. (https://doi.org/10.1016/j. freeradbiomed.2011.06.022)

Mauvoisin D, Atger F, Dayon L, Núñez Galindo A, Wang J, Martin E, Da Silva L, Montoliu I, Collino S, Martin F-P, et al. 2017 Circadian and feeding rhythms orchestrate the diurnal liver acetylome. Cell Reports 20 1729-1743. (https://doi.org/10.1016/j.celrep.2017.07.065)

McCarthy JJ, Andrews JL, McDearmon EL, Campbell KS, Barber BK, Miller BH, Walker JR, Hogenesch JB, Takahashi JS \& Esser KA 2007 Identification of the circadian transcriptome in adult mouse skeletal muscle. Physiological Genomics 31 86-95. (https://doi.org/10.1152/ physiolgenomics.00066.2007)

McDearmon EL, Patel KN, Ko CH, Walisser JA, Schook AC, Chong JL, Wilsbacher LD, Song EJ, Hong H-K, Bradfield CA, et al. 2006 Dissecting the functions of the mammalian clock protein BMAL1 by tissue-specific rescue in mice. Science 314 1304-1308. (https://doi. org/10.1126/science.1132430)
Meijer JH, Watanabe K, Schaap J, Albus H \& Détári L 1998 Light responsiveness of the suprachiasmatic nucleus: long-term multiunit and single-unit recordings in freely moving rats. Journal of Neuroscience 18 9078-9087.

Mitchell RA 1996 Stoichiometry of glucose oxidation when linked to ATP synthesis. Biochemical Education 24 207-208. (https://doi. org/10.1016/S0307-4412(96)00104-5)

Mitra K 2013 Mitochondrial fission-fusion as an emerging key regulator of cell proliferation and differentiation. BioEssays 35 955-964. (https://doi.org/10.1002/bies.201300011)

Mosko SS \& Moore RY 1979 Neonatal suprachiasmatic nucleus lesions: effects on the development of circadian rhythms in the rat. Brain Research 164 17-38. (https://doi.org/10.1016/0006-8993(79)90003-9)

Nakahata Y, Kaluzova M, Grimaldi B, Sahar S, Hirayama J, Chen D, Guarente LP \& Sassone-Corsi P 2008 The NAD+-dependent deacetylase SIRT1 modulates CLOCK-mediated chromatin remodeling and circadian control. Cell 134 329-340. (https://doi. org/10.1016/j.cell.2008.07.002)

Nakahata Y, Sahar S, Astarita G, Kaluzova M \& Sassone-Corsi P 2009 Circadian control of the NAD+ salvage pathway by CLOCK-SIRT1 Science 324 654-657. (https://doi.org/10.1126/science.1170803)

Nakamura W, Yamazaki S, Nakamura TJ, Shirakawa T, Block GD \& Takumi T 2008 In vivo monitoring of circadian timing in freely moving mice. Current Biology 18 381-385. (https://doi.org/10.1016/j. cub.2008.02.024)

Neufeld-Cohen A, Robles MS, Aviram R, Manella G, Adamovich Y, Ladeuix B, Nir D, Rousso-Noori L, Kuperman Y, Golik M, et al. 2016 Circadian control of oscillations in mitochondrial rate-limiting enzymes and nutrient utilization by PERIOD proteins. PNAS 113 E1673-E1682. (https://doi.org/10.1073/pnas.1519650113)

Ni H-M, Williams JA \& Ding W-X 2015 Mitochondrial dynamics and mitochondrial quality control. Redox Biology 4 6-13. (https://doi. org/10.1016/j.redox.2014.11.006)

Oliva-Ramírez J, Moreno-Altamirano MMB, Pineda-Olvera B, CauichSánchez P \& Sánchez-García FJ 2014 Crosstalk between circadian rhythmicity, mitochondrial dynamics and macrophage bactericidal activity. Immunology 143 490-497. (https://doi.org/10.1111/imm.12329)

Panda S, Antoch MP, Miller BH, Su AI, Schook AB, Straume M, Schultz PG, Kay SA, Takahashi JS \& Hogenesch JB 2002 Coordinated transcription of key pathways in the mouse by the circadian clock. Cell 109 307-320. (https://doi.org/10.1016/S0092-8674(02)00722-5)

Peek CB, Affinati AH, Ramsey KM, Kuo H-Y, Yu W, Sena LA, Ilkayeva O, Marcheva B, Kobayashi Y, Omura C, et al. 2013 Circadian clock NAD+ cycle drives mitochondrial oxidative metabolism in mice. Science 342 1243417. (https://doi.org/10.1126/science.1243417)

Peek CB, Ramsey KM, Levine DC, Marcheva B, Perelis M \& Bass J 2015 Circadian regulation of cellular physiology. Methods in Enzymology 552 165-184. (https://doi.org/10.1016/bs.mie.2014.10.006)

Pfeifer U 1981 Autophagic vacuoles in heart muscle and liver. A comparative morphometric study including circadian variations in meal-fed rats. Journal of Molecular and Cellular Cardiology 13 37-49. (https://doi.org/10.1016/0022-2828(81)90227-3)

Pfeifer U \& Scheller H 1975 A morphometric study of cellular autophagy including diurnal variations in kidney tubules of normal rats. Journal of Cell Biology 64 608-621. (https://doi.org/10.1083/jcb.64.3.608)

Rambold AS, Kostelecky B, Elia N \& Lippincott-Schwartz J 2011 Tubular network formation protects mitochondria from autophagosomal degradation during nutrient starvation. PNAS 108 10190-10195. (https://doi.org/10.1073/pnas.1107402108)

Ramsey KM, Yoshino J, Brace CS, Abrassart D, Kobayashi Y, Marcheva B, Hong H-K, Chong JL, Buhr ED, Lee C, et al. 2009 Circadian clock feedback cycle through NAMPT-mediated NAD+ biosynthesis. Science 324 651-654. (https://doi.org/10.1126/science.1171641)

Reczek CR \& Chandel NS 2015 ROS-dependent signal transduction. Current Opinion in Cell Biology 33 8-13. (https://doi.org/10.1016/j. ceb.2014.09.010)

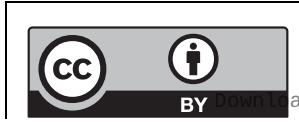

This work is licensed under a Creative Common Attribution 4.0 Unported License. 
Rey G, Cesbron F, Rougemont J, Reinke H, Brunner M \& Naef F 2011 Genome-wide and phase-specific DNA-binding rhythms of BMAL1 control circadian output functions in mouse liver. PLoS Biology (edited by A Kramer) 9 e1000595. (https://doi.org/10.1371/journal. pbio.1000595)

Rhee SG \& Kil IS 2016 Mitochondrial H2O2 signaling is controlled by the concerted action of peroxiredoxin III and sulfiredoxin: linking mitochondrial function to circadian rhythm. Free Radical Biology and Medicine 100 73-80. (https://doi.org/10.1016/j. freeradbiomed.2016.10.011)

Rich PR 2003 The molecular machinery of Keilin's respiratory chain. Biochemical Society Transactions 31 1095-1105. (https://doi. org/10.1042/bst0311095)

Rodgers JT, Lerin C, Haas W, Gygi SP, Spiegelman BM \& Puigserver P 2005 Nutrient control of glucose homeostasis through a complex of PGC-1alpha and SIRT1. Nature 434 113-118. (https://doi. org/10.1038/nature03354)

Rutter J, Reick M, Wu LC \& McKnight SL 2001 Regulation of clock and NPAS2 DNA binding by the redox state of NAD cofactors. Science 293 510-514. (https://doi.org/10.1126/science.1060698)

Saito T \& Sadoshima J 2015 Molecular mechanisms of mitochondrial autophagy/mitophagy in the heart. Circulation Research 116 1477-1490. (https://doi.org/10.1161/CIRCRESAHA.116.303790)

Sato T \& Kawamura H 1984 Circadian rhythms in multiple unit activity inside and outside the suprachiasmatic nucleus in the diurnal chipmunk (Eutamias sibiricus). Neuroscience Research 1 45-52. (https://doi.org/10.1016/0168-0102(84)90029-4)

Scrima R, Cela O Merla G, Augello B, Rubino R, Quarato G, Fugetto S, Menga M, Fuhr L, Relógio A, et al. 2016 Clock-genes and mitochondrial respiratory activity: evidence of a reciprocal interplay. Biochimica et Biophysica Acta (BBA): Bioenergetics 1857 1344-1351. (https://doi.org/10.1016/j.bbabio.2016.03.035)

Sebastián D, Palacín M \& Zorzano A 2017 Mitochondrial dynamics: coupling mitochondrial fitness with healthy aging. Trends in Molecular Medicine 23 201-215. (https://doi.org/10.1016/j. molmed.2017.01.003)

Sena LA \& Chandel NS 2012 Physiological roles of mitochondrial reactive oxygen species. Molecular Cell 48 158-167. (https://doi. org/10.1016/j.molcel.2012.09.025)

Sengupta S, Yang G, O'Donnell JC, Hinson MD, McCormack SE, Falk MJ, La P, Robinson MB, Williams ML, Yohannes MT, et al. 2016 The circadian gene Rev-erb $\alpha$ improves cellular bioenergetics and provides preconditioning for protection against oxidative stress. Free Radical Biology and Medicine 93 177-189. (https://doi.org/10.1016/j. freeradbiomed.2016.02.004)

Simon N, Papa K, Vidal J, Boulamery A \& Bruguerolle B 2003 Circadian rhythms of oxidative phosphorylation: effects of rotenone and melatonin on isolated rat brain mitochondria. Chronobiology International 20 451-461. (https://doi.org/10.1081/CBI-120021385)
Stavinoha MA, RaySpellicy JW, Essop MF, Graveleau C, Abel ED, Hart-Sailors ML, Mersmann HJ, Bray MS \& Young ME 2004 Evidence for mitochondrial thioesterase 1 as a peroxisome proliferator-activated receptor- $\alpha$-regulated gene in cardiac and skeletal muscle. American Journal of Physiology: Endocrinology and Metabolism 287 E888-E895. (https://doi.org/10.1152/ajpe ndo.00190.2004)

Stringari C, Wang H, Geyfman M, Crosignani V, Kumar V, Takahashi JS, Andersen B \& Gratton E 2015 In vivo single-cell detection of metabolic oscillations in stem cells. Cell Reports 10 1-7. (https://doi. org/10.1016/j.celrep.2014.12.007)

Twig G, Elorza A, Molina AJA, Mohamed H, Wikstrom JD, Walzer G, Stiles L, Haigh SE, Katz S, Las G, et al. 2008 Fission and selective fusion govern mitochondrial segregation and elimination by autophagy. EMBO Journal 27 433-446. (https://doi.org/10.1038/sj. emboj.7601963)

van Moorsel D, Hansen J, Havekes B, Scheer FAJL, Jörgensen JA, Hoeks J, Schrauwen-Hinderling VB, Duez H, Lefebvre P, Schaper NC, et al. 2016 Demonstration of a day-night rhythm in human skeletal muscle oxidative capacity. Molecular Metabolism 5 635-645. (https:// doi.org/10.1016/j.molmet.2016.06.012)

Wai T \& Langer T 2016 Mitochondrial dynamics and metabolic regulation. Trends in Endocrinology and Metabolism 27 105-117. (https://doi.org/10.1016/j.tem.2015.12.001)

Woldt E, Sebti Y, Solt LA, Duhem C, Lancel S, Eeckhoute J, Hesselink MKC, Paquet C, Delhaye S, Shin Y, et al. 2013 Rev-erb- $\alpha$ modulates skeletal muscle oxidative capacity by regulating mitochondrial biogenesis and autophagy. Nature Medicine 19 1039-1046. (https://doi.org/10.1038/nm.3213)

Wu Z, Puigserver P, Andersson U, Zhang C, Adelmant G, Mootha V, Troy A, Cinti S, Lowell B, Scarpulla RC, et al. 1999 Mechanisms controlling mitochondrial biogenesis and respiration through the thermogenic coactivator PGC-1. Cell 98 115-124. (https://doi. org/10.1016/S0092-8674(00)80611-X)

Xu Y-Q, Zhang D, Jin T, Cai D-J, Wu Q, Lu Y, Liu J \& Klaassen CD 2012 Diurnal variation of hepatic antioxidant gene expression in mice. PLoS ONE (edited by P Mukhopadhyay) 7 e44237. (https://doi. org/10.1371/journal.pone.0044237)

Youle RJ \& Narendra DP 2011 Mechanisms of mitophagy. Nature Reviews Molecular Cell Biology 12 9-14. (https://doi.org/10.1038/nrm3028)

Zhang R, Lahens NF, Ballance HI, Hughes ME \& Hogenesch JB 2014a A circadian gene expression atlas in mammals: implications for biology and medicine. PNAS 111 16219-16224. (https://doi.org/10.1073/ pnas.1408886111)

Zhang D, Tong X, Arthurs B, Guha A, Rui L, Kamath A, Inoki K Yin L $2014 b$ Liver Clock Protein BMAL1 Promotes de Novo Lipogenesis through Insulin-mTORC2-AKT Signalling. Journal of Biological Chemistry 289 25925-25935. (https://doi.org/10.1074/jbc. M114.567628)

Received in final form 23 December 2017

Accepted 29 January 2018

Accepted Preprint published online 29 January 2018 http://jme.endocrinology-journals.org https://doi.org/10.1530/JME-17-0196
(C) 2018 The authors Published by Bioscientifica Ltd. Printed in Great Britain

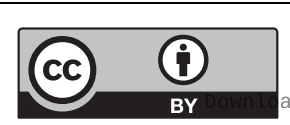

This work is licensed under a Creative Common Attribution 4.0 Unported License.

ded from Bioscientifica.com at 04/26/2023 02:47:41AM 